\title{
Experimental transmission of Sparicotyle chrysophrii (Monogenea: Polyopisthocotylea) to gilthead seabream (Sparus aurata) and histopathology of the infection
}

\author{
Ariadna Sitjà-Bobadilla and Pilar Alvarez-Pellitero
}

Instituto de Acuicultura de Torre de la Sal, CSIC, Torre de la Sal s/n, 12595 Ribera de Cabanes, Castellón, Spain

\begin{abstract}
The polyopisthocotylean Sparicotyle chrysophrii (Van Beneden et Hesse, 1863) was experimentally transmitted to gilthead seabream (Sparus aurata L.) by exposure to eggs (EGT) and by cohabitation with naturally parasitized fish (CT). In EGT trials, the infection was successfully transmitted by introducing containers with monogenean eggs in the fish tanks, with the highest infection level (85.7\% prevalence, 3.3 mean intensity) achieved at 6 weeks post exposure (p.e.) to the infection dose of 650 eggs per tank. In CT trials, the progression of the infection was faster and reached higher levels than in EGT. When using small fish juveniles ( $30 \mathrm{~g})(\mathrm{CT}-2)$, infection reached $100 \%$ prevalence (mean intensity 8 monogeneans/fish) at 5 weeks p.e., but no eggs could be found in the fish even 10 weeks p.e. By contrast, when larger juveniles (150 g) were used (CT-1), infection levels were lower, but mature adults with eggs were detected starting from 8 weeks p.e. The effect of the parasite on the condition factor, haematocrit, haemoglobin concentration $(\mathrm{Hb})$, red blood cell counts, mean corpuscular haemoglobin concentration (MCHC), mean corpuscular haemoglobin content $(\mathrm{MCH})$ and mean cellular volume $(\mathrm{MCV})$ of infected fish was studied in $\mathrm{CT}$ trials. The infection produced hypochromic anaemia, since $\mathrm{Hb}$ concentration significantly decreased at 5 and 10 weeks p.e. in CT-2 and at 8 weeks p.e. in CT-1. MCHC was significantly lower in parasitized than in control fish at 5 and 8 weeks p.e. in CT-2 and CT-1, respectively. Also in CT-1, MCH was lower and circulating immature erythrocytes, granulocytes and plasma cells were higher in infected fish than in control ones at 8 weeks p.e. The histopathological effects of the monogenean on the gills of naturally infected fish consisted of lamellar shortening, clubbing and synechiae. The proliferation of the epithelial tissue produced fusion of secondary lamellae, and abundant chloride cells were observed.
\end{abstract}

Key words: Monogenea, gills, ectoparasites, haematology, anaemia, Sparidae

Polyopisthocotyleans are pathogenic to economically important fish around the world (Thoney and Hargis 1991, Ernst et al. 2002, Ogawa 2002, Hayward 2004, Hutson et al. 2007). Amongst them, Sparicotyle (syn. Microcotyle) chrysophrii (Van Beneden et Hesse, 1863) is one of the most threatening ectoparasites for gilthead seabream (Sparus aurata L.) culture. It has been reported to produce mortalities in farmed fish (Faisal and Iman 1990, Sanz 1992, Alvarez-Pellitero 2004), and it is frequently found in mixed infections with other parasites and bacterial infections (Padrós and Crespo 1995, Cruz e Silva et al. 1997, Caffara et al. 2005). Previous parasitological surveys have shown its high prevalence in sea cages (Diamant 2001, Mladineo 2005, Fioravanti et al. 2006, Vagianou et al. 2006, Sitjà-Bobadilla, Redondo and Alvarez-Pellitero, unpublished results), but data differ greatly depending on the surveyed geographical area. Parasite invasion in sea cages is more difficult to control than in other type of facilities. The limited use and efficacy of chemicals and drugs for treatment makes the situation even more difficult to handle (Sitjà-Bobadilla et al. 2006).

Under these culture and epidemiological circumstances, effective management strategies to prevent monogenean epizootics need to incorporate accurate knowledge of the mode of transmission and host-parasite interaction (Altizer et al. 2006). Several experimental transmission trials have been used for other microcotylids, with variable results depending on the host-parasite model, the infective dose and the type of transmission. Thus, specific information has to be obtained for each host-parasite system, and this is lacking for S. chrysophrii. Furthermore, disease signs commonly reported by fish farmers and fish pathologists include lethargy, emaciation and anaemia, but there are no data on the actual histopathological and haematological effects of this monogenean in parasitized fish. Thus, the aim of this work was to determine the dynamics of the transmission of S. chrysophrii under laboratory conditions and the pathological effects on naturally and experimentally infected gilthead seabream. 


\section{MATERIALS AND METHODS}

Fish and experimental design. Naturally infected gilthead seabream were obtained from commercial fish farms and maintained at the facilities of the Instituto de Acuicultura de Torre de la Sal (IATS), in 500-litre fibre-glass tanks. Upon arrival, 10 fish per sampled stock were killed and their gills examined to ascertain the presence of the parasite. Fish from infected stocks were used both as a source of parasite eggs, and as donor fish (D) in the cohabitation trials. In addition, the gills of some of these naturally infected fish were used to study the histopathological effect of the monogenean with light microscopy (LM). Non-parasitized fish were also obtained from commercial farms and, after assessing the absence of the monogenean, they were used as recipient $(\mathrm{R})$ fish.

Two types of transmission trials were performed: by contact with S. chrysophrii eggs (EGT) and by cohabitation (CT) with parasitized animals. The source of infection in each trial, as well as the experimental conditions are explained below. Unless otherwise stated, all experimental tanks received sand and meshfiltered $(10 \mu \mathrm{m})$ seawater (standard flow-through supply from a pump on shore, $37.5 \%$ o salinity, flow $=201 / \mathrm{min}$ ), with an oxygen content higher than $85 \%$ saturation. Water was heated when necessary in order to keep temperature always above $18^{\circ} \mathrm{C}$. Water temperature range in each transmission trial is indicated in Tables 1 and 3. Photoperiod followed the natural cycle at IATS facilities $\left(40^{\circ} 5^{\prime} \mathrm{N}, 0^{\circ} 10^{\prime} \mathrm{E}\right)$ and all fish were fed daily a commercial dry pellet diet at about $1 \%$ of body weight.

Parasite diagnosis. The presence of $S$. chrysophrii was detected by two methods (F, S). For the fresh (F) diagnosis, fish were slightly anesthetized with MS-222 (Sigma, Saint Louis, MO) $(100 \mathrm{mg} / \mathrm{l})$ and gill scrapings taken from the external-most gill arch (gill arch I) were examined using LM. The first arch was selected because it is the most parasitized with respect to the remaining arches (Oliver 1984). The F method was used in the first samplings of some trials to provide an initial estimation of the progression of the infection and for selecting the timing of the subsequent lethal samplings in which a more precise diagnosis method was applied (S method, see next). For the stereomicroscope (S) diagnosis, fish were killed by a blow on the head under anaesthesia (MS-222, $100 \mathrm{mg} / \mathrm{l}$ ), bled to diminish blood content in gills, all their gills arches excised and examined under the stereomicroscope. In both cases, the number and type of stages of the monogenean were recorded. With both methods, the prevalence and the mean intensity of infection of the parasite were calculated according to Bush et al. (1997). When using the F method, intensity of infection was semiquantitatively evaluated following a conventional scale from $1+$ to $6+$, according to the number of monogeneans per squash (40 observational fields) at $\times 120(1+=1-2$ parasites; $2+=3-5 ; 3+=6-8 ; 4+=9-11$; $5+=12-14 ; 6+\geq 15)$. Intensity was quantitatively registered (number of monogenean specimens per fish) with the S method.

Histopathology. The damage invoked by the monogenean was studied in naturally parasitized fish (D) coming from commercial cage farms and kept at IATS facilities. After necropsy, gills were fixed in $10 \%$ neutral buffered formalin, dehydrated in graded ethanol series following standard histological procedures, embedded in Technovit resin (Kulzer, Heraeus, Germany), $2 \mu \mathrm{m}$-sectioned, stained with toluidine blue and examined with LM.

Egg-transmission (EGT). Sparicotyle chrysophrii eggs were harvested from tanks holding parasitized fish. For this purpose, a PVC ring provided with a $250 \mu \mathrm{m}$-mesh was left for 2-3 days floating on the water at the upper layer of the tank. After washing the mesh with seawater (SW), the resulting volume was left to settle down for $1 \mathrm{~h}$ in a 1-litre graded cylinder, and the obtained sediment was screened under a stereomicroscope. The collected eggs were immersed in Petri dishes containing sterilized SW with an antibiotic-antimycotic mixture $\left(100 \mathrm{U} \mathrm{ml}^{-1}\right.$ penicillin, $100 \mu \mathrm{g} \mathrm{ml}^{-1}$ streptomycin and $0.25 \mathrm{~g} \mathrm{ml}^{-1}$ amphotericin B) (SW-PSA) to prevent bacteria and fungi proliferation, and counted. SW-PSA did not affect egg hatching (Sitjà-Bobadilla et al. 2006). Eggs were used in two different transmission trials, as detailed below.

In EGT-1 and EGT-2 trials, PVC cylinders provided with a $500 \mu \mathrm{m}$-mesh at both sides were set floating horizontally in a 90-litre tank holding $\mathrm{R}$ fish. The cylinders contained 350 and 650 eggs, respectively, and were designed to allow hatching larvae to exit and get in contact with fish. During the first hour water flow was closed and then, the flow was set to the minimum to favour contact of any recently hatched larvae and to assure fish survival along the experiment. The cylinders were left in the tanks until the end of the trial. At this time, they were opened to check egg hatching. Control (CTRL) fish not exposed to eggs were kept in another tank.

At different times post exposure (p.e.), R and CTRL fish were sampled for the detection of the monogenean. Details on the host weight and samplings of the three trials can be found in Table 1.

Transmission by cohabitation (CT). The initial parasite burden of $\mathrm{D}$ fish was determined by examining fish with the $\mathrm{S}$ method before starting the cohabitation, and $\mathrm{R}$ fish were marked with passive integrated transponder (PIT) tags to differentiate them. PIT-tags were injected into the dorso-lateral musculature of the fish with a commercial pistol implanter (Trovan, Spain) producing no harm or behaviour alteration. Fish were identified by a portable reader (LID-560, Trovan) passed over their surface when sampled. Two cohabitation trials were performed. In CT-1,

Table 1. Transmission trials of Sparicotyle chrysophrii by contact of gilthead seabream (Sparus aurata) with monogenean eggs. Data on the resulting infection in receptor $(\mathrm{R})$ fish and sampling methods are provided. $\mathrm{P}=$ prevalence; $\mathrm{MI}=$ mean intensity.

\begin{tabular}{|c|c|c|c|c|c|c|c|c|c|c|}
\hline \multirow[t]{2}{*}{ Trial } & \multirow{2}{*}{$\begin{array}{l}\text { Source of } \\
\text { infection } \\
\text { (No. eggs) }\end{array}$} & \multicolumn{2}{|c|}{ Initial R fish } & \multicolumn{4}{|c|}{ Samplings } & \multicolumn{3}{|c|}{ Infection in $\mathrm{R}$ fish } \\
\hline & & $\begin{array}{c}\text { Mean } \\
\text { weight }(\mathrm{g})\end{array}$ & $\mathrm{n}$ & $\begin{array}{l}\text { Temperature } \\
\text { range }\left({ }^{\circ} \mathrm{C}\right)^{\mathrm{a}}\end{array}$ & $\begin{array}{l}\text { Wks. } \\
\text { p.e. }\end{array}$ & $\begin{array}{c}\text { Type of } \\
\text { diagnosis }^{\mathrm{b}}\end{array}$ & $\mathrm{n}$ & $\mathrm{P}(\%)$ & MI & Stages $^{c}$ \\
\hline EGT-1 & 350 & 30.1 & 30 & $24.4-26.9$ & 6 & S & 20 & 5 & 1 & A \\
\hline EGT-2 & 650 & 30.2 & 30 & $25-26.9$ & 6 & $\mathrm{~S}$ & 7 & 85.7 & 3.3 & $\mathrm{~J}, \mathrm{~A}, \mathrm{E}$ \\
\hline & & & & $25.9-25.2$ & 9 & S & 7 & 0 & 0 & - \\
\hline
\end{tabular}

${ }^{a}$ Water temperature range during the indicated period.

b The monogenean was diagnosed by the $\mathrm{F}$ (fresh) or the $\mathrm{S}$ (stereomicroscope) method.

${ }^{c}$ Parasite stages: $\mathrm{J}=$ juveniles, $\mathrm{A}=$ adults, $\mathrm{E}=$ eggs. 
Table 2. Experimental conditions for the transmission of Sparicotyle chrysophrii by cohabitation $(\mathrm{CT})$ of receptor $(\mathrm{R})$ with parasitized donor (D) gilthead seabream (Sparus aurata). $\mathrm{P}=$ prevalence; $\mathrm{MI}=$ mean intensity.

\begin{tabular}{ccccccccc}
\hline Trial & \multicolumn{3}{c}{ S. chrysophrii-infected fish (D) } & & \multicolumn{2}{c}{ Initial R fish } \\
\cline { 2 - 5 } \cline { 8 - 9 } & $\begin{array}{c}\text { Mean } \\
\text { weight }(\mathrm{g})\end{array}$ & $\mathrm{n}$ & $\begin{array}{c}\mathrm{D} / \mathrm{R} \\
\text { ratio }\end{array}$ & $\mathrm{P}(\%)$ & MI & & $\begin{array}{c}\text { Mean } \\
\text { weight }(\mathrm{g})\end{array}$ & $\mathrm{n}$ \\
\hline $\mathrm{CT}-1$ & 60.1 & $56 \times 3$ & 1.86 & 96.6 & 8.6 & & 150.3 & $30 \times 3$ \\
CT-2 & 76.8 & 10 & 0.5 & 100 & 13.6 & & 30.9 & 20 \\
\hline
\end{tabular}

three replicated 500-litre tanks with $\mathrm{D}(\mathrm{n}=56)+\mathrm{R}(\mathrm{n}=30)$ fish/ each were set up. Another tank was set as control (CTRL) with non-parasitized fish kept under the same conditions, but without contact with D fish. Gill samples of R fish (7/replicate) were taken at 3 and 5 weeks p.e. and diagnosed by the F method. At 8 and 20 weeks p.e., $\mathrm{R}$ and CTRL fish were killed, diagnosed by the $\mathrm{S}$ method, and blood was taken from the caudal vessels with heparinised syringes for haematological determinations. In CT-2, R and CTRL groups were also set up (one replicate/group; 200-litre tanks). Fish from both groups were sampled $(\mathrm{n}=7)$ at 5 and 10 weeks p.e., diagnosed by the $\mathrm{S}$ method and blood was taken for haematological determinations.

In all the samplings involving the $\mathrm{S}$ method, animals were weighed, measured and the condition factor $(\mathrm{CF})$ was calculated with the formula: (weight/length $\left.{ }^{3}\right) * 100$. Details on the experimental conditions can be found in Tables 2 and 3 .

Haematology. In CT samplings involving the S method, heparinised blood was kept on ice and used immediately for the measurement of haematological parameters. The haematocrit level $(\mathrm{Hc})$ was measured after centrifugation of the blood in heparinised capillary tubes at $1500 \mathrm{~g}$ for $30 \mathrm{~min}$. Haemoglobin concentration $(\mathrm{Hb})$ was determined with a HemoCue B-Haemoglobin Analyser ${ }^{\circledR}$ (AB, Leo Diagnostic, Sweden), which uses a modified azide methaemoglobin reaction for haemoglobin quantification. Blood was drawn into disposable microcuvettes which contain reagents in dried form that produce the red blood cell lysis and the conversion of haemoglobin to methaemoglobin by sodium nitrate, which is then combined with azide. The absorbance of the azide methaemoglobin is then photometrically measured at $565 \mathrm{~nm}$ and $880 \mathrm{~nm}$. Red blood cell (RBC) counts were made in a Neubauer chamber, using an isotonic solution $(1 \% \mathrm{NaCl})$. Mean corpuscular haemoglobin concentration (MCHC), mean corpuscular haemoglobin content $(\mathrm{MCH})$ and mean cellular volume $(\mathrm{MCV})$ were also calculated. In addition, at the 8-weeks sampling (CT-1), blood smears were obtained and stained with May-Grünwald Giemsa. In stained smears, leucocytes, thrombocytes and immature erythrocytes were counted and calculated with reference to the number of RBC per $\mathrm{mm}^{3}$. In addition, white cell composition was determined, distinguishing neutrophils, eosinophils, lymphocytes, monocytes and plasma cells according to their morphology, size and staining characteristics as established by López-Ruiz et al. (1992).

Statistics. A student $t$-test or a Mann-Whitney rank sum test was used to compare the biometrical and haematological values of CTRL and R fish in CT trials. All statistical analyses were performed using Sigma Stat software (SPSS Inc., Chicago, IL), and the minimum significance level was set at $P<0.05$.

\section{RESULTS}

Parasite transmission. Table 1 shows the results of the EGT trials. The parasite was transmitted by leaving eggs floating inside cylinders, and the highest infection level $(85.7 \%)$ in $\mathrm{R}$ fish was obtained with the highest egg dose (EGT-2) at 6 weeks p.e. At this time, all the stages (juveniles, adults and eggs) were present, but the parasite disappeared at the last sampling ( 9 weeks p.e.). At the end of EGT trials, no unhatched eggs were present in the containers.

Transmission by cohabitation resulted in higher infection levels than by EGT (Table 3). In CT-1, using large $\mathrm{R}$ juveniles $(150 \mathrm{~g})$, the infection progressed slowly, but it was maintained even 20 weeks p.e. By contrast, in CT-2, with smaller $\mathrm{R}$ juveniles ( $30 \mathrm{~g}$ ), the parasite was established earlier, reaching $100 \%$ in just 5 weeks. Parasites matured progressively in CT-1, with only juveniles (Fig. 1) being detected at 3 weeks p.e., and adults (Fig. 2) and eggs (Fig. 3) appearing progressively at subsequent samplings. In CT-2, no eggs were detected, even 10 weeks p.e.

Haematological study. In CT-1, R fish showed significantly lower levels of $\mathrm{Hb}, \mathrm{MCH}$ and $\mathrm{MCHC}$, and significantly higher values of immature erythrocytes, total leucocytes, neutrophils, eosinophils and plasma cells than CTRL animals at 8 weeks p.e. (Table 4). In CT-2, haemoglobin was also significantly lower in R fish than in CTRL ones at 5 and 10 weeks p.e., and MCHC was significantly decreased at 5 weeks p.e. as well (Table 5). In both trials, no significant differences between $\mathrm{R}$ and CTRL fish were found in $\mathrm{CF}$.

Histopathological study. Sparicotyle chrysophrii was firmly attached to the gill filament by its paired haptoral clamps (Figs. 4, 5), each single lamella being grasped by each clamp (Figs. 6, 7). The larger the fluke body, the higher the number of clamps that could attach to the epithelium. The haptor of a single adult specimen was capable of broaching at least 41 lamellae. Occasionally, adults were attached simultaneously to two neighbouring filaments (Fig. 8). The firm gripping of lamellae by clamp sclerites produced lamellar synechiae at the site of attachment (Figs. 6, 7) and lamellar clubbing, which could result in the disruption of the epithelium and marginal blood vessels. The epithelium grasped by the clamps showed no apparent host cellular reaction. When the parasite detached from the filament, lamellar shortening and clubbing was even more evident (Figs. 9, 10). The most characteristic cellular reaction consisted of a proliferation of the epithelial tissue resulting in the fusion of the secondary lamellae (Fig. 9). No leucocytic infiltration or necrosis was observed, but abundant chloride cells were evident (Figs. 9, 10). The monogenean body, due to its large size, also produced compression of the lamellar structure (Fig. 11). Epitheliocystis was also present in the gills of few Sparicotyle-infected fish (Fig. 11). 
Table 3. Transmission trials of Sparicotyle chrysophrii by cohabitation with parasitized (D) gilthead seabream (Sparus aurata). Data on the resulting infection in receptor $(\mathrm{R})$ fish and sampling methods are provided. $\mathrm{P}=$ prevalence; $\mathrm{MI}=$ mean intensity.

\begin{tabular}{|c|c|c|c|c|c|c|c|}
\hline \multirow[t]{2}{*}{ Trial } & \multirow{2}{*}{$\begin{array}{l}\text { Temperature } \\
\text { range }\left({ }^{\circ} \mathrm{C}\right)\end{array}$} & \multicolumn{3}{|c|}{ Samplings } & \multicolumn{3}{|c|}{ Infection in R fish } \\
\hline & & $\begin{array}{l}\text { Wks. } \\
\text { p.e. }\end{array}$ & $\begin{array}{c}\text { Type of } \\
\text { diagnosis }\end{array}$ & $\mathrm{n}$ & $\mathrm{P}(\%)$ & MI & Stages $^{\mathrm{b}}$ \\
\hline \multirow[t]{4}{*}{$\overline{\mathrm{CT}}-1$} & $25-26.9$ & 3 & $\mathrm{~F}$ & 21 & 4.8 & $1+$ & $\mathrm{J}$ \\
\hline & $26.9-25.9$ & 5 & $\mathrm{~F}$ & 21 & 19.1 & $1+$ & $\mathrm{J}, \mathrm{A}$ \\
\hline & $25.9-25.2$ & 8 & S & 15 & 66.7 & 2.2 & A, E \\
\hline & $25.2-8$ & 20 & $\mathrm{~S}$ & 9 & 77.8 & 3 & $\mathrm{~A}, \mathrm{E}$ \\
\hline \multirow[t]{2}{*}{$\overline{\mathrm{CT}}-2$} & $18 \pm 0.5$ & 5 & $\mathrm{~S}$ & 7 & 100 & 8 & $\mathrm{~J}>\mathrm{A}$ \\
\hline & $18 \pm 0.5$ & 10 & S & 7 & 87.5 & 4.7 & $\mathrm{~J}<\mathrm{A}$ \\
\hline
\end{tabular}

${ }^{a}$ The monogenean was diagnosed by the $\mathrm{F}$ (fresh) or $\mathrm{S}$ (stereomicroscope) methods. ${ }^{b}$ Parasite stages: $\mathrm{J}=$ juveniles; $\mathrm{A}=$ adults; $\mathrm{E}=$ eggs.

Table 4. Condition factor (CF) and haematological values (mean $\pm \mathrm{SEM}$ ) of control (CTRL) and receptor (R) gilthead seabream (Sparus aurata) after 8 weeks of transmission of Sparicotyle chrysophrii by cohabitation (CT-1). Haemoglobin concentration $(\mathrm{Hb})$, haematocrit $(\mathrm{Hc})$, mean cellular volume $(\mathrm{MCV})$, mean corpuscular haemoglobin content $(\mathrm{MCH})$, mean corpuscular haemoglobin concentration (MCHC).

\begin{tabular}{lll}
\hline & CTRL & $\mathrm{R}$ \\
\hline $\mathrm{CF}$ & $2.4 \pm 0.04$ & $2.4 \pm 0.03$ \\
$\mathrm{Hb}(\mathrm{g} / \mathrm{dl})$ & $7.73 \pm 0.2$ & $5.95 \pm 0.2^{* *}$ \\
$\mathrm{Hc}(\%)$ & $39.1 \pm 0.9$ & $42.5 \pm 1.1$ \\
$\mathrm{MCV}(\mathrm{fl})$ & $125.8 \pm 4.4$ & $138.1 \pm 7.2$ \\
$\mathrm{MCH}(\mathrm{pg})$ & $24.8 \pm 0.9$ & $19.3 \pm 1.1 * *$ \\
MCHC $(\mathrm{g} / \mathrm{l})$ & $198.7 \pm 6.3$ & $140.6 \pm 5.1^{* *}$ \\
Total RBC $\left(10^{3} / \mathrm{mm}^{3}\right)$ & $3139 \pm 79.6$ & $3160.7 \pm 134.2$ \\
Young RBC $\left(10^{3} / \mathrm{mm}^{3}\right)$ & $20.4 \pm 2.1$ & $42.3 \pm 4.9^{* *}$ \\
Total leucocytes $\left(10^{3} / \mathrm{mm}^{3}\right)$ & $18.5 \pm 1.6$ & $30.6 \pm 2.6^{* *}$ \\
Thrombocytes $\left(10^{3} / \mathrm{mm}^{3}\right)$ & $28.1 \pm 2.9$ & $24.3 \pm 4.9$ \\
Neutrophils $\left(10^{3} / \mathrm{mm}^{3}\right)$ & $6.1 \pm 0.5$ & $10.5 \pm 0.8^{* *}$ \\
Eosinophils $\left(10^{3} / \mathrm{mm}^{3}\right)$ & $5.8 \pm 0.9$ & $9.9 \pm 1.4^{*}$ \\
Lymphocytes $\left(10^{3} / \mathrm{mm}^{3}\right)$ & $6.2 \pm 0.6$ & $8.9 \pm 4.8$ \\
Plasma cells $\left(10^{3} / \mathrm{mm}^{3}\right)$ & $0.26 \pm 0.08$ & $0.65 \pm 0.08^{* *}$ \\
Monocytes $\left(10^{3} / \mathrm{mm}^{3}\right)$ & $0.13 \pm 0.05$ & $0.29 \pm 0.1$ \\
\hline
\end{tabular}

Statistically significant difference between R and CTRL at $P<0.05$ (*), $P<0.001(* *)$.

Table 5. Condition factor (CF) and haematological values (mean \pm SEM) of control (CTRL) and receptor (R) gilthead seabream (Sparus aurata) after 5 and 10 weeks post exposure (p.e.) to Sparicotyle chrysophrii by cohabitation (CT-2).

\begin{tabular}{llllll}
\hline & \multicolumn{3}{c}{5 weeks p.e. } & & \multicolumn{2}{c}{10 weeks p.e. } \\
\cline { 2 - 3 } \cline { 3 - 5 } & CTRL & $\mathrm{R}$ & CTRL & $\mathrm{R}$ \\
$\mathrm{CF}$ & $2.3 \pm 0.06$ & $2.4 \pm 0.05$ & $1.6 \pm 0.1$ & $1.8 \pm 0.03$ \\
$\mathrm{Hb}(\mathrm{g} / \mathrm{dl})$ & $6.5 \pm 0.3$ & $4.9 \pm 0.4^{*}$ & $5.4 \pm 0.2$ & $4.6 \pm 0.2^{*}$ \\
$\mathrm{Hc}(\%)$ & $35.8 \pm 3.3$ & $30.9 \pm 3.2$ & $34.7 \pm 2.2$ & $36 \pm 3.5$ \\
$\mathrm{MCHC}(\mathrm{g} / \mathrm{l})$ & $186.6 \pm 6.6$ & $162.9 \pm 4^{*}$ & $159.8 \pm 7.9$ & $133.1 \pm 12.1$ \\
\hline
\end{tabular}

Statistically significant difference between R and CTRL at $P<0.05(*)$. For explanations of abbreviations see Table 4.

\section{DISCUSSION}

Sparicotyle chrysophrii was successfully transmitted to naïve gilthead seabream by egg exposure (EGT) and cohabitation (CT) with parasitized fish. In EGT trials by keeping the eggs until the end of the experiments in the tanks within an appropriate container in which eggs can mature, hatched larvae were capable of infecting fish, and a clear effect of the exposure dose was observed. The obtained prevalence of infection was high, notably in EGT-2, but the intensity of infection was lower than in naturally parasitized gilthead seabream. This experimental procedure was chosen in an effort to mimic the conditions in sea cages, in which larvae from eggs laid progressively can hatch gradually and settle in fish in successive infective waves. However, the data obtained in EGT trials showed the difficulty to achieve high numbers of eggs and high intensity of infection in receptor fish. Similarly, the exposure of Sebastes schlegeli to embryonated eggs of Microcotyle sebastis resulted in 100\% prevalence in three weeks, but with lower number of parasites than in naturally infected fish (Kim and Choi 1998). According to the available data, the exposure of fish to larvae of monogeneans results in variable levels of infection depending on the host-parasite model (Rubio-Godoy and Tinsley 2002, Glennon et al. 2007). As in the present study, a clear larval dose-effect on parasite settlement was observed in tiger puffer (Takifugu rubripes) exposed to oncomiracidia of Heterobothrium okamotoi (Chigasaki et al. 2000). A pattern of initial increase and then decline in infection, as found in EGT-3, has also been observed in other monogenean infections (Mansell et al. 2005) and under other experimental conditions in gilthead seabream (Sitjà-Bobadilla et al. 2006). Some authors have suggested that this decline could be due to the immune response of the host and the development of resistance (Sterud et al. 1998, Linderstrøm and Buchmann 2000, Mansell et al. 2005, Rubio-Godoy and Tinsley 2008b).

In CT trials, the progression of the infection was faster and reached higher levels when using smaller fish (CT-2 vs CT-1), in spite of the lower infective pressure (D/R ratio $=0.5$ in CT-2 vs 1.86 in CT-1). It is likely that the respiratory water current of the larger fish was stronger than that of smaller fish and therefore hampered the settlement of the oncomiracidia, or the larger fish just have a higher immunocompetence. Although the prevalence of infection reached high levels $(100 \%$ in CT-2 and $77.8 \%$ in CT-1), the intensity of infection was again low and far from the values registered in fish from outbreak samplings in the Spanish Mediterranean (with a maximum mean value of 70.6 monogeneans per fish) (Sitjà-Bobadilla, Redondo and Alvarez-Pellitero, unpublished results). Therefore, the experimental conditions for the CT did not mimic closely enough the cage-culture conditions. This could be due to a lower fish density in the tanks than in the cages, and to the characteristics of the tanks, which offer 


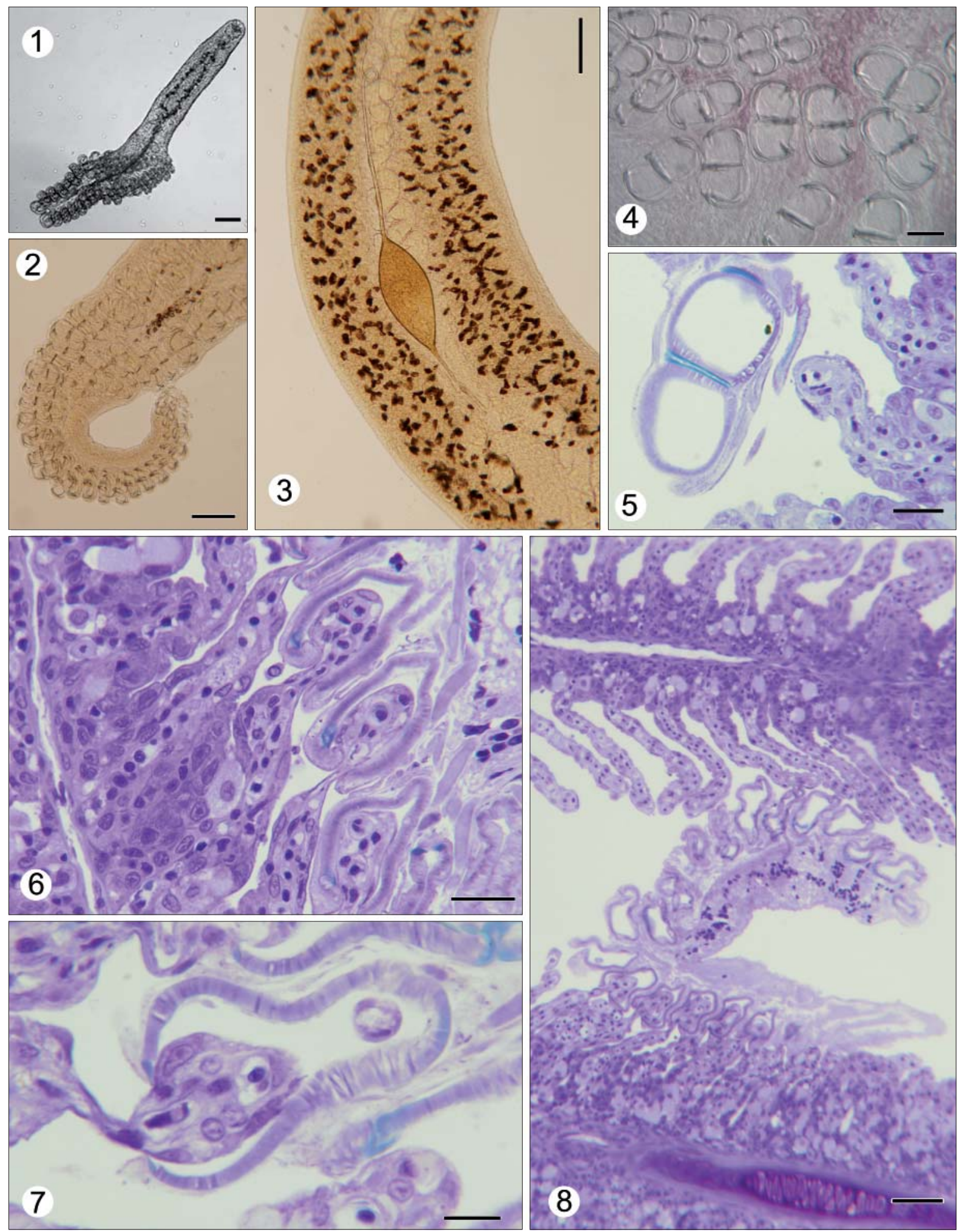

Figs. 1-8. Light microscopy images of Sparicotyle chrysophrii obtained from lactophenol-mounted (Figs. 1-3) or fresh specimens (Fig. 4), and toluidine blue-stained sections of gilthead seabream (Sparus aurata) gills (Figs. 5-8). Fig. 1. Juvenile specimen. Fig. 2. Detail of the haptor of an adult specimen. Fig. 3. Detail of an adult specimen with one egg. Fig. 4. Nomarski view of the clamps from an adult specimen. Note the different size of the clamps depending on their position in the haptor. Fig. 5. Transverse section of a clamp. Fig. 6. Detail of the clamp-lamellae interaction in a zip-mode. Fig. 7. One clipped lamella is shown. Note the precise grasp of the clamp sclerites. Fig. 8. Adult specimen with its haptor reaching two opposite secondary lamellae. Scale bars: Figs. $1,4=50 \mu \mathrm{m}$; Figs. $2,3=100 \mu \mathrm{m}$; Figs. 5, 6, $8=20 \mu \mathrm{m}$; Fig. $7=5 \mu \mathrm{m}$. 

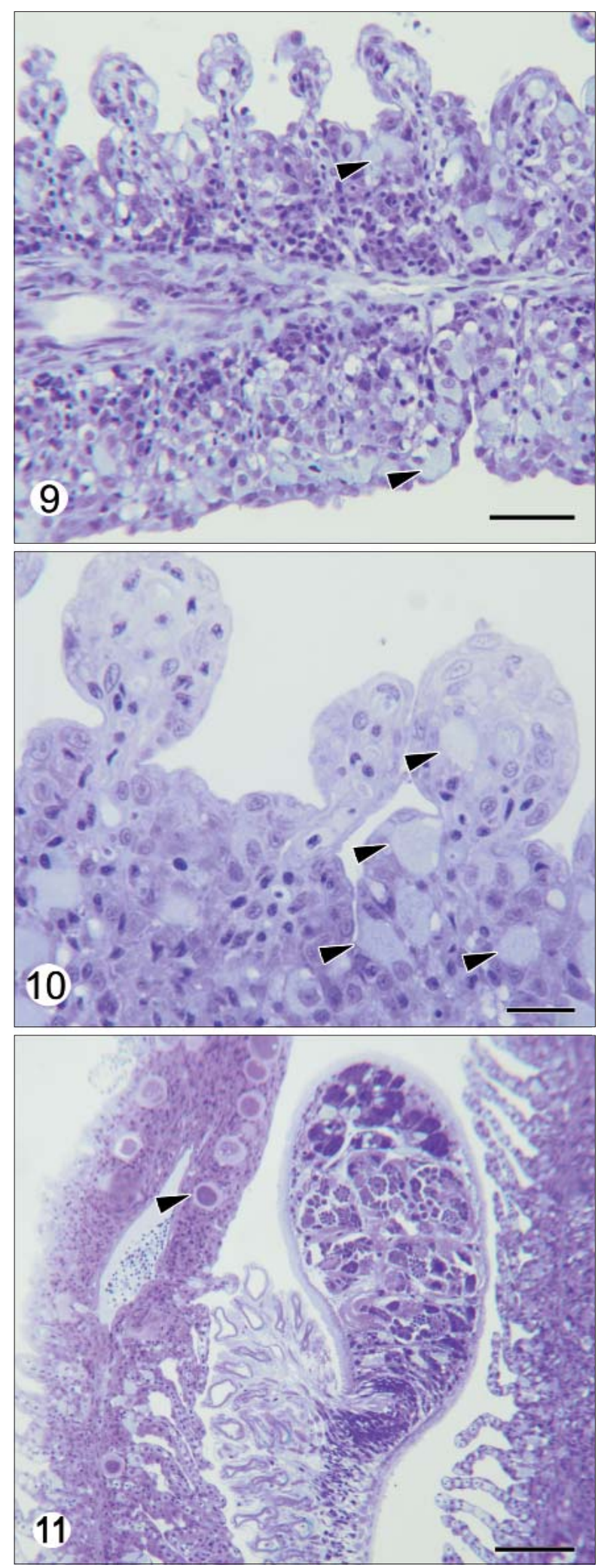

a less favourable surface for the entanglement of the long and hook-ended filaments of the eggs of the parasite than the culture nets. By contrast, Seriola lalandi was successfully infected by cohabitation with Zeuxapta seriolae-parasitized fish, reaching a peak of 565.9 monogeneans/fish at 4 weeks (Mansell et al. 2005).

The haematological study performed in CT trials clearly demonstrated that the parasite induces anaemia, even with low intensity of infection. Hb concentration was significantly lower in R than in CTRL fish at 5 and 10 weeks p.e. in CT-2 trial, in small gilthead seabream harbouring an average of 8 and 4.7 monogenean specimens, respectively, and also in larger $\mathrm{R}$ juveniles at 8 weeks p.e., with infection levels as low as 2.2 specimens/fish (CT-1). A negative correlation was established between the number of parasites and $\mathrm{Hb}$ levels in Japanese flounders (Paralichthys olivaceus) infected by the diclidophorid Neoheterobothrium hirame (Mushiake et al. 2001) and S. lalandi infected by Z. seriolae (Mansell et al. 2005). The two indicators of the amount of haemoglobin in red blood cells (MCH, MCHC) were also significantly lower in R fish in CT-1, which indicates that erythrocytes were hypochromic. Hypochromic anaemias usually overlap with microcytic anaemias, but this was not the case, since MCV was not reduced in infected fish. Total RBC counts were similar in R and CTRL fish, but immature erythrocytes were significantly higher in R fish in CT-1. Similarly, immature erythrocyte appeared frequently in Japanese flounder naturally (Mushiake et al. 2001) and experimentally infected with $N$. hirame (Yoshinaga et al. 2001). Any considerable acceleration of the rate of erythrocyte production is generally accompanied by the appearance of less mature forms in the blood stream (Dawson 1933). Therefore, it can be deduced that the loss of red blood cells produced by the parasite is initially compensated by the activation of haematopoiesis, leading to the increased appearance of immature erythrocytes in circulating blood, which carry lower amounts of haemoglobin. Recently, a histopathological study of splenic melanomacrophage centres has revealed not only a dramatic increase in their number in Sparicotyle-infected gilthead seabream, but also an increased content of haemosiderin within them, which is probably due to a high catabolism of damaged erythrocytes (De Vico et al. 2008).

Anaemia is a common effect of blood-feeding ectoparasites and can lead to the death of their hosts due to their diminished capacity for oxygen transport. Other disease signs commonly reported are gill paleness, plasma metabolite changes, and reduced swimming performance

Figs. 9-11. Light microscopy images of Sparicotyle chrysophrii from toluidine blue-stained sections of gilthead seabream (Sparus aurata) gills. Fig. 9. Panoramic view of the histopathological effect after detaching of the parasite. Note the lamellar shortening and clubbing at one side and the lamellar fusion at the opposite one. Fig. 10. Detail of the clubbing. Note the proliferation of chloride cells in Figs. 9 and 10 (arrowheads). Fig. 11. Panoramic view of a large adult monogenean occupying the space between two primary lamellae and compressing the secondary lamellae. Note the co-infection (epitheliocystis) (arrowhead). Scale bars: Figs. 9, $10=40 \mu \mathrm{m}$; Fig. $11=100 \mu \mathrm{m}$. 
(Grimnes and Jakobsen 1996, Horton and Okamura 2003, Wagner and McKinley 2004, Tsotetsi et al. 2005). The high mortality found in Discocotyle sagittata-infected farmed rainbow trout was attributed to the induced anaemia (Gannicott 1997) and a correlation between the anaemic condition of Japanese flounder and the intensity of infection by $N$. hirame has been shown (Yoshinaga et al. 2000, Yoshinaga et al. 2001, Anshary et al. 2002). Furthermore, negative relationships between parasite abundance and haematocrit (Montero et al. 2004, Paperna et al. 1984, Yoshinaga et al. 2001, Rubio-Godoy 2004), and between parasite burden and the condition factor (Shirakashi et al. 2006, Rubio-Godoy and Tinsley 2008a) have been reported mainly in heavy polyopisthocotylean infections. As in experimentally infected amberjacks (Seriola dumerili) (Montero et al. 2004), in our CT trials the condition factor was similar in R and CTRL fish. Most probably, this indicator is decreased when the intensity of infection is higher than the levels achieved in the experimental transmission.

Another effect of the infection in CT-1 was leucocytosis, mainly due to the significantly higher levels of neutrophils, eosinophils and plasma cells. Although data on the composition of circulating leucocytes in parasitic infections are scarce in fish, most reports point to increased levels of leucocytes and some types of granulocytes. This is the case of $N$. hirame-infected Japanese flounder, which showed increased ratios of granulocytes and monocytes/ macrophages in peripheral blood (Nakayasu et al. 2003, 2005). Thus far, several studies have detected specific antibodies in fish infected by monogeneans, including polyopisthocotyleans, but their involvement in protection is still unknown in most cases (reviewed in Rubio-Godoy 2007). The increased number of plasma cells found in CT-1 R fish could be indicative of a probable production of specific antibodies against S. chrysophrii. All these data point to the existence of a cell and humoral immune response, but its relevance to the protection of gilthead seabream remains to be established.

The histopathological damage produced by S. chrysophrii in our study was marked and unequivocal compared to that of other pathogens detected in the gills, and similar to that invoked by Z. seriolae in Seriola spp. (Montero et al. 2004, Mansell et al. 2005). Each S. chrysophrii clamp grasped only one secondary lamella, in contrast with other polyopisthocotyleans, such as Kuhnia scombri (Llewellyn 1954) and Z. seriolae (syn. Z. japonica) (Anshary and Ogawa 2001, Montero et al. 2004) that can attach up to two secondary lamellae. Some polyopisthocotyleans in- duce strong cellular reactions at the site of the attachment, and this reaction may vary depending on the host and the involved part of the anatomy of the fish (González et al. 2004, Nakayasu et al. 2005, Rubio-Godoy 2007). However, no strong local leucocyte reaction was observed in the current study, as also occurred with the Z. japonica in Seriola dumerili (Anshary and Ogawa 2001). The observation of abundant chloride cells in our infected fish could be a response to the ionoregulatory challenge induced by the epithelial injuries provoked by the parasite. Lamellar chloride cell proliferation is a common response of fish to enhance the ion transporting capacity of the gill under situations that disturb ionic homeostasis (Sakuragi et al. 2003, Benli et al. 2008). However, such a response elicits concurrent detrimental effects on respiratory gas transfer because of a thickening of the blood-to-water diffusion barrier (Perry 1998). In the only available report on the effect of monogenean infections on chloride cells, European seabass (Dicentrarchus labrax) gills parasitized by Diplectanum aequans showed a reduction in the number of chloride cells (Dezfuli et al. 2007).

In conclusion, the pathological effects of S. chrysophrii in S. aurata probably result in respiratory dysfunction due to the mechanical lesions and obstruction of water flow between gill filaments by the massive body of the flukes and due to the anaemia induced by the haematophagous nature of the parasite and by the haemorrhages provoked by the disruption of the epithelial and vascular structures. As lower food intake has been documented in gilthead seabream with high monogenean burdens (Sitjà-Bobadilla et al. 2006), we cannot discard the possible contribution of anorexia to the anaemic condition of fish in such heavy infections.

The present results have demonstrated the ease of S. chrysophrii transmission by two different methods that try to mimic the conditions in sea-cages, and the negative effect of the infection on some blood parameters, even with moderate numbers of parasites per host. Further studies are needed to analyse in depth the mechanisms of anaemia.

Acknowledgements. This work was supported by research grants from the Spanish Ministerio de Educación, Cultura y Deporte (project MAR-98/1000), the Spanish Ministerio de Ciencia y Tecnología (project No. AGL-2002-0475-C02). The authors are grateful to M. Alonso and P. Cabrera for excellent assistance in experimental infections and samplings, to J. Montfort and L. Rodríguez for histological processing, to M. Cerezo for contributing to some haematological determinations and to local fish farmers for providing experimental fish. 


\section{REFERENCES}

Altizer S., Dobson A., Hosseini P., Hudson P., Pascual M., Rohani P. 2006: Seasonality and the dynamics of infectious diseases. Ecol. Lett. 9: 467-484.

Alvarez-Pellitero P. 2004: Report about fish parasitic diseases. In: P. Alvarez-Pellitero, J.L. Barja, B. Basurco, F. Berthe and A.E. Toranzo (Eds.), Mediterranean Aquaculture Diagnostic Laboratories. Zaragoza: CIHEAM/FAO. Série B: Etudes et Recherches, No. 49, Options Méditerranéennes, pp. 103-129.

Anshary H., OGawa K. 2001: Microhabitats and mode of attachment of Neoheterobothrium hirame, a monogenean parasite of Japanese flounder. Fish Pathol. 36: 21-26.

Anshary H., Yamamoto E., Miyanaga T., Ogawa K. 2002: Infection dynamics of the monogenean Neoheterobothrium hirame among young wild Japanese flounder in the western Sea of Japan. Fish Pathol. 37: 131-140.

Benli A.C.K., Köksal G., ÖzKul A. 2008: Sublethal ammonia exposure of Nile tilapia (Oreochromis niloticus L.): effects on gill, liver and kidney histology. Chemosphere 72: 1355-1358.

Bush A.O., Lafferty K.D., Lotz J.M., Shostak A.W. 1997: Parasitology meets ecology on its own terms: Margolis et al. revisited. J. Parasitol. 83: 575-583.

Caffara M., Quaglio F., Fioravanti M.L., Gustinelli A., Marcer F., Moscato M., Caggiano M. 2005: Coinfezione da Polysporoplasma sparis (Myxozoa) e Sparicotyle chrysophrii (Monogenea) in orata (Sparus aurata). Atti Del Xii Convegno Nazionale S.I.P.I., Cesenatico (FC), 29-30 Settembre - 1 Ottobre 2005, p. 47.

Chigasaki M., Nakane M., Ogawa K., Wakabayashi T. 2000: Standardized method for experimental infection of tiger puffer Takifugu rubripes with oncomiracidia of Heterobothrium okamotoi (Monogenea: Diclidophoridae) with some data on the oncomiracidial biology. Fish Pathol. 35: 215-221.

Cruz e Silva M.P., Freitas M.S., Orge M.L. 1997: Co-infection by monogenetic trematodes of the genus Microcotyle, Beneden \& Hesse, 1863, Lamellodiscus ignoratus Palombi, 1943, the protozoan Trichodina sp. Ehrenberg, 1838 and the presence of epitheliocystis, Vibrio alginolyticus and V. vulnificus in cultured seabream (Sparus aurata L.) in Portugal. Bull. Eur. Assoc. Fish Pathol. 17: 40-42.

Dawson A.B. 1933: The relative numbers of immature erythrocytes in the circulating blood of several species of marine fishes. Biol. Bull. 64: 33-43.

De Vico G., Cataldi M., Carella F., Marino F., Passantino A. 2008: Histological, histochemical and morphometric changes of splenic melanomacrophage centers (Smmcs) in Sparicotyle-infected cultured sea breams (Sparus aurata). Immunopharmacol. Immunotoxicol. 30: 27-35.

Dezfuli B.S., Giari L., Simoni E., Menegatti R., Shinn A.P., Manera M. 2007: Gill histopathology of cultured European sea bass, Dicentrarchus labrax (L.), infected with Diplectanum aequans (Wagener 1857) Diesing 1958 (Diplectanidae: Monogenea). Parasitol. Res. 100: 707-713.

Diamant A. 2001: Cross-infections between marine cage-cultured stocks and wild fish in the northern Red Sea: is the environment at risk? In: C.J. Rodgers (Ed.), Proc. Int. Conf. Risk Analysis in Aquatic Animal Health, Paris, France, pp. 202-208.

Ernst I., Whittington I., Corneille S., Talbot C. 2002: Monogenean parasites in sea-cage aquaculture. Austasia Aquac. 2: 46-48.

Faisal M., Iman E.A. 1990: Microcotyle chrysophrii (Monogenea: Polyopisthocotylea), a pathogen of cultured and wild gilt- head sea bream, Sparus aurata. In: F.O. Perkins and T.C. Cheng (Eds.), Pathology in Marine Science. Academic Press, San Diego, CA, pp. 283-290.

Fioravanti M.L., Caffara M., Florio D., Gustinelli A., MarcER F. 2006: A parasitological survey of European sea bass (Dicentrarchus labrax) and Gilthead sea bream (Sparus aurata) cultured in Italy. Vet. Res. Comm. 30: 249-252.

Gannicott A.M. 1997: The biology of Discocotyle sagittata (Monogenea) infecting trout. PhD Thesis, University of Bristol, $312 \mathrm{pp}$.

Glennon V., Chisholm L.A., Whittington I.D. 2007: Experimental infections, using a fluorescent marker, of two elasmobranch species by unciliated larvae of Branchotenthes octohamatus (Monogenea: Hexabothriidae): invasion route, host specificity and post-larval development. Parasitology 134: 1243-1252.

González P., Sánchez M.I., Chirivella J., Carbonell E., Riera F., Grau A. 2004: A preliminary study on gill metazoan parasites of Dentex dentex (Pisces: Sparidae) from the western Mediterranean Sea (Balearic Islands). J. Appl. Ichthyol. 20: 276-281.

Grimnes A., Jakobsen P.J. 1996: The physiological effects of salmon lice infection on post-smolt of Atlantic salmon. J. Fish Biol. 48: 1179-1194.

HaYward C. 2004: Polyopisthocotyleans and their impact on marine fish culture. In: K. Buchmann (Ed.), Diagnosis and Control of Fish Diseases. Frederiksberg Bogtrykkeri A/S, Frederiksberg, Denmark, p. 11.

Horton T., Okamura B. 2003: Post-haemorrhagic anaemia in sea bass, Dicentrarchus labrax (L.), caused by blood feeding of Ceratothoa oestroides (Isopoda: Cymothoidae). J. Fish Dis. 26: 401-406.

Hutson K.S., Ernst I., Whittington I.D. 2007: Risk assessment for metazoan parasites of yellowtail kingfish Seriola lalandi (Perciformes: Carangidae) in South Australian sea-cage aquaculture. Aquaculture 271: 85-99.

Kiм K.H., Сног E.S. 1998: Treatment of Microcotyle sebastis (Monogenea) on the gills of cultured rockfish (Sebastes schlegeli) with oral administration of mebendazole and bithionol. Aquaculture 167: 115-121.

Lindenstrøm T., Buchmann K. 2000: Acquired resistance in rainbow trout against Gyrodactylus derjavini. J. Helminthol. 74: 155-160.

Llewellyn J. 1954: Observations on the food and the gut pigment of the Polyopisthocotylea (Trematoda: Monogenea). Parasitology 44: 428-437.

López-Ruiz A., Esteban M.A., Meseguer J. 1992: Blood cells of the gilthead sea bream (Sparus aurata L.): light and electron microscopic studies. Anat. Rec. 234: 161-171.

Mansell B., Powell M.D., Ernst I., NowaK B.F. 2005: Effects of the gill monogenean Zeuxapta seriolae (Meserve, 1938) and treatment with hydrogen peroxide on pathophysiology of kingfish, Seriola lalandi Valenciennes, 1833. J. Fish Dis. 28: 253262.

Mladineo I. 2005: Parasite communities of Adriatic cage-reared fish. Dis. Aquat. Org. 64: 77-83.

Montero F.E., Crespo S., Padrós F., De la Gándara F., García A., RAGA J.A. 2004: Effects of the gill parasite Zeuxapta seriolae (Monogenea: Heteraxinidae) on the amberjack Seriola dumerili Risso (Teleostei: Carangidae). Aquaculture 232: 153163.

Mushiake K., Mori K., Arimoto M. 2001: Epizootiology of anemia in wild Japanese flounder. Fish Pathol. 36: 125-132. 
Nakayasu C., Tsutsumi N., Oseko N., Hasegawa S. 2005: Role of cellular response in elimination of the monogenean Neoheterobothrium hirame in Japanese flounder Paralichthys olivaceus. Dis. Aquat. Org. 64: 127-134.

Nakayasu C., Tsutsumi N., Yoshitomi T., Yoshinaga T., KuMAGAI A. 2003: Identification of Japanese flounder leucocytes involved in the host response to Neoheterobothrium hirame. Fish Pathol. 38: 9-14.

OGawA K. 2002: Impacts of diclidophorid monogenean infections on fisheries in Japan. Int. J. Parasitol. 32: 373-380.

Oliver G. 1984: Microcotyle chrysophrii Van Beneden et Hesse, 1863 (Monogenea, Polyopisthocotylea, Microcotylidae) parasite de Sparus aurata dans les étangs littoraux du LanguedocRoussillon (France). Bull. Soc. Zool. France - Evol. Zool. 109: 113-118.

PAdrós F., Crespo S. 1995: Proliferative epitheliocystis associated with monogenean infection in juvenile sea bream Sparus aurata in the North East of Spain. Bull. Eur. Assoc. Fish Pathol. 15: 42-44.

Paperna I., Diamant A., Overstreet R.M. 1984: Monogenean infestations and mortality in wild and cultured Red-Sea fishes. Helgol. Mar. Res. 37: 445-462.

Papoutsoglou S.E., Costello M.J., Stamou E., Tzina G. 1996: Environmental conditions at sea-cages, and ectoparasites on farmed European sea-bass, Dicentrarchus labrax (L.), and gilthead sea-bream, Sparus aurata L., at two farms in Greece. Aquacult. Res. 27: 25-34.

Perry S.F. 1998: Relationship between branchial chloride cells and gas transfer in fresh water fish. Comp. Biochem. Physiol. 119A: 9-16.

Rubio-Godoy M. 2004: Host-parasite interactions between trout and the monogenean Discocotyle sagittata. $\mathrm{PhD}$ Thesis. University of Bristol, $410 \mathrm{pp}$.

Rubio-Godoy M. 2007: Fish host-monogenean parasite interactions, with special reference to Polyopisthocotylea. In: L.I. Terrazas (Ed.), Advances in the Immunobiology of Parasitic Diseases. Research Signpost, Kerala, India, pp. 91-109.

Rubio-Godoy M., Tinsley R.C. 2002: Trickle and single infection with Discocotyle sagittata (Monogenea: Polyopisthocotylea): effect of exposure mode on parasite abundance and development. Folia Parasitol. 49: 269-278.

Rubio-Godoy M., Tinsley R.C. 2008a: Recruitment and effects of Discocotyle sagittata (Monogenea) infection on farmed trout. Aquaculture 274: 15-23.

Rubio-Godoy M., Tinsley R.C. 2008b: Transmission dynamics of Discocotyle sagittata (Monogenea) infection on farmed trout

Received 22 December 2008 interpreted from parasite population age structure. Aquaculture 275: 34-41.

SANZ F. 1992: Mortality of cultured sea bream (Sparus aurata) caused by an infection with a trematode of the genus Microcotyle. Bull. Eur. Assoc. Fish Pathol. 12: 186-188.

Sakuragi M.M., Sanches J.R., Fernandes M.N. 2003: Gill chloride proliferation and respiratory responses to hypoxia of the neotropical erythrinid fish Hoplias malabaricus. J. Comp. Physiol. 173: 309-317.

Shirakashi S., Yamada T., Yamada T., Ogawa K. 2006: Infection dynamics of Neoheterobothrium hirame (Monogenea) on juvenile olive flounder, Paralichthys olivaceus (Temminck \& Schlegel), in coastal waters of Japan. J. Fish Dis. 29: 319-329.

Sitjà-Bobadilla A., De Felipe M.C., Alvarez-Pellitero P. 2006: In vivo and in vitro treatments against Sparicotyle chrysophrii (Monogenea: Microcotylidae) parasitizing the gills of gilthead sea bream (Sparus aurata L.). Aquaculture 261: 856-864.

Sterud E., Harris P.D., Bakke T. A. 1998: The influence of Gyrodactylus salaris Malmberg, 1957 (Monogenea) on the epidermis of Atlantic salmon, Salmo salar L. and brook trout, Salvelinus fontinalis (Mitchill): experimental studies. J. Fish Dis. 21: 257263.

Thoney D.A., Hargis J. 1991: Monogenea (Platyhelminthes) as hazards for fish in confinement. Ann. Rev. Fish Dis. 1: 133-153.

Tsotetsi A.M., Avenant-Oldewage A., Mashego S.N. 2005: Aspects of the pathology of Lamproglena clariae (Copepoda: Lernaeidae) on gills of Clarias gariepinus from the Vaal River system, South Africa. Afr. Zool. 40: 169-178.

Vagianou S., Athanassopoulou F., Ragias V., Di Cave D., Leontides L., Golomazou E. 2006: Prevalence and pathology of ectoparasites of Mediterranean Sea bream and sea bass reared under different environmental and aquaculture conditions. Isr. J. Aquacult. Bamidgeh 58: 78-88.

Wagner G.N., McKinley R.S. 2004: Anaemia and salmonid swimming performance: the potential effects of sub-lethal sea lice infection. J. Fish Biol. 64: 1027-1038.

Yoshinaga T., Kamaishi T., Segawa I., Kumagai A., Nakayasu C., Yamano K., Takeuchi T., Sorimachi M. 2000: Hematology, histopathology and the monogenean Neoheterobothrium hirame infection in anemic flounder. Fish Pathol. 35: 131-136.

Yoshinaga T., Kamaishi T., Segawa I., Yamano K., Ikeda H., Sorimachi M. 2001: Anemia caused by challenges with the monogenean Neoheterobothrium hirame in the Japanese flounder. Fish Pathol. 36: 13-20.

Accepted 5 May 2009 